\title{
CONDIÇÃO FINANCEIRA ATRAVÉS DE INDICADORES BASEADOS EM ATIVOS E PASSIVOS ATUARIAIS: UMA ANÁLISE NO INSTITUTO DE PREVIDÊNCIA DO ESTADO DA PARAÍBA
}

FINANCIAL CONDITION THROUGH INDICATORS BASED ON ASSETS AND LIABILITIES: AN ANALYSIS AT THE INSTITUTE OF PREVENTION OF THE PARAÍBA STATE

\author{
FÁBIO MARISCANO FAGUNDES \\ MFCONT Contabilidade Empresarial \\ VERA LÚCIA CRUZ \\ Universidade Federal da Paraíba \\ RAMON RODRIGUES DOS SANTOS \\ Universidade Federal de Pernambuco
}

Recebido em 14/04/18

Avaliado pelo sistema double blind review e solicitado revisões em 26/04/18

Aceito para publicação pelo Editor Chefe Dr. Leonardo José Seixas Pinto em 14/05/18 e publicado em 20/06/18

\section{RESUMO}

O estudo objetivou evidenciar a situação financeira e atuarial do Instituto de Previdência do Estado da Paraíba - Paraíba Previdência ou PBPREV através dos indicadores propostos por Lima e Diniz (2016). Para isto, realizou-se uma pesquisa documental, no qual foram coletadas as informações dos balanços financeiros e patrimoniais, além de outras demonstrações da PBPREV no período de 2013 a 2016, e, na sequência, aplicados os índices propostos pelos autores. Com base nas análises realizadas, foi evidenciado que a situação atuarial do PBPREV se apresenta com uma tendência para o déficit, e já a financeira, está equilibrada, em virtude dos recursos provenientes das transferências governamentais, e das que são previstas nos cálculos atuariais, mas que, no entanto, em todo o período analisado, encontra-se no limite. O estudo concluiu que a PBPREV não possui uma condição financeira e atuarial satisfatória que possa garantir a continuidade das atividades do instituto no médio prazo, o que pode comprometer a solvência do ente. Ademais, este estudo sugere a realização de medidas corretivas que busquem garantir seu equilíbrio financeiro e atuarial, cujos procedimentos podem ajudar a corrigir alguns problemas que possam comprometer a saúde financeira e atuarial da PBPREV.

Palavras-chave: Equilíbrio financeiro e atuarial; Indicadores; PBPREV.

\section{ABSTRACT}

The study aimed to highlight the financial and actuarial situation of Institute of Prevention of Paraiba State through the indicators proposed by Lima and Diniz (2016). For this, a documentary research was carried out, through a case study, in which the information of the financial and equity balance sheets was collected, as well as other demonstrations of the PBPREV entity in the period from 2013 to 2016, and, subsequently, were applied the indexes proposed by the authors. Based on the analyzes carried out, the study concluded that the PBPREV does not have a satisfactory financial and actuarial condition that can guarantee the continuity of the institute's activities in the medium term, which may compromise the entity's solvency. The study suggested that corrective measures be taken to ensure the financial and actuarial balance of the entity, which procedures may help to correct some of the problems that may be jeopardizing PBPREV's financial and actuarial health.

Keywords: Financial and Actuarial Equilibrium; Indicators; PBPREV. 


\section{INTRODUÇÃO}

Os Regimes Próprios de Previdência Social somam mais de R \$ 175 bilhões em patrimônio e constituem mais de 2.024 planos municipais e 27 estaduais, de acordo com o Sistema de Informações dos Regimes Públicos de Previdência Social do Ministério da Previdência Social (CADPREV, 2016). Ainda, segundo a mesma instituição, existem 130 planos em extinção na Paraíba, além de 70 planos ativos e 2 planos em processo de extinção.

O Instituto de Previdência do Estado da Paraíba - Paraíba Previdência, ou simplesmente, PBPREV, possuía, em 2013, um total de 54.976 servidores, 32.057 inativos e 10.642 pensionistas (CADPREV, 2016). Os recursos do PBPREV, em sua maioria, são provenientes dos próprios entes e a outra parte da contribuição dos participantes que são obtidas para formar as reservas e garantir o equilíbrio financeiro e atuarial. Os percentuais para o financiamento dos planos estão inseridos na Emenda Constitucional n 43 (BRASIL, 2003) cujo limite máximo para desconto dos participantes é de $11 \%$. Ademais, de acordo com o art. $2^{\circ}$ da Lei ${ }^{\circ} 9.717$ (BRASIL, 1998), a contribuição do governo não pode ser inferior ao valor do segurado e nem superior ao limite dessa contribuição.

Esses recursos arrecadados dos participantes, bem como dos entes, obedecem aos limites de aplicação definidos na Resolução n 3.922 do Conselho Monetário Nacional (CMN, 2010) que os separa em dois segmentos: renda fixa e renda variável. Essas aplicações servirão para a formação das reservas e dos recursos que irão subsidiar os benefícios aos segurados, mantendo o equilíbrio financeiro e atuarial. Segundo os dados do Ministério da Previdência Social (MPS, 2016), 85,15\% estão direcionados para a aplicação em renda fixa e $8 \%$ em renda variável.

De acordo com o Demonstrativo Anual de Investimentos e Recursos (DAIR) de 2016, o ente possuía $\mathrm{R} \$ 158.729 .127,66$ (cento e cinquenta e oito milhões setecentos e vinte e nove mil cento e vinte e sete reais e sessenta e seis centavos) em ativos vinculados pela Lei $n^{\circ} 9.939$ (PARAÍBA, 2012), e, mesmo com essa reserva, o Demonstrativo de Resultados da Avaliação Atuarial (DRRA), em 2016, projetou o valor atual dos salários futuros em R $\$ 2.715 .915 .917,58$ (dois bilhões, setecentos e quinze milhões novecentos e quinze mil e cinquenta e oito centavos) e um déficit atuarial de R\$ 117.061.479,78 (cento e dezessete milhões, sessenta e um mil quatrocentos e setenta e nove reais e setenta e oito centavos), motivando assim, há época, um plano de amortização desse déficit em 35 (trinta e cinco) anos.

Da mesma forma que as informações supracitadas foram disponibilizadas por números, as análises podem ser feitas por indicadores, tendo em vista que os Regimes Próprios de Previdência Social (RPPSs), assim como as empresas, podem ser analisadas por algumas técnicas encontradas na literatura, sejam estas por análises vertical, horizontal, de tendências, analises financeira comparada, entre outras.

Nesse sentido, Lima e Diniz (2016) afirmam que essas técnicas visam extrair informações financeiras das demonstrações contábeis aplicadas ao setor público e relatórios fiscais, apresentando aos usuários da informação um formato que facilite o desempenho financeiro da empresa. Dessa forma, serão utilizados, para este artigo, indicadores para evidenciar a situação financeira e atuarial do RPPS, relacionando-os para cada resultado que venha a retratar a situação financeira e atuarial do plano.

De acordo com o Relatório de Auditoria Operacional do Tribunal de Contas do Estado da Paraíba (TCE/PB), através do Processo Técnico n 16.017 (TCE/PB, 2015), a situação dos RPPS brasileiros tem se agravado ao longo dos anos, consistindo em uma grave ameaça para o equilíbrio das finanças públicas. Em complemento, o relatório do Tribunal de Contas da União (TCU), aponta que o déficit atuarial agregado dos estados e Distrito Federal praticamente dobrou ao longo dos exercícios de 2011 a 2014, alcançando aproximados 50\% do Produto Interno Bruto (PIB).

A DRAA da PBPREV parte de um déficit atuarial de R\$ 117.061.479,78 (cento e dezessete milhões, sessenta e um mil quatrocentos e setenta e nove reais e setenta e oito centavos) que serão amortizados no período de 35 anos. Não obstante, apresenta um superávit financeiro de R\$ 59.093.860,38 (cinquenta e nove milhões, noventa e três mil, oitocentos e sessenta reais e trinta e oito centavos) para cobrir um total de 5.398 servidores sem critério diferenciado para aposentadoria, o 
que representa um volume financeiro anual de $\mathrm{R} \$ 77.576 .146,37$ (setenta e sete milhões, quinhentos e setenta e seis mil, cento e quarenta e seis reais e trinta e sete centavos), englobando as aposentadorias programadas por morte e invalidez permanente, além de pensão por morte de servidor em atividade.

Nesse sentido, mesmo diante de toda a ação dos órgãos reguladores e fiscalizadores, os Regimes Próprios possuem uma peculiaridade na aplicação dos recursos arrecadados, uma vez a legislação determina a Portaria MPS n 402 (BRASIL, 2008) nos artigos 19 a 23 que sejam destinados aos diversos tipos de investimentos para que os recursos sejam capitalizados e multiplicados. Diante do exposto, chega-se ao seguinte problema: Qual a condição financeira e atuarial do Regime de Previdência do Estado da Paraíba - PBPREV com base nos indicadores? Para isso, com a finalidade de responder esta pergunta, foi traçado o objetivo de evidenciar a situação financeira e atuarial da PBPREV através dos indicadores, analisando a capacidade dos ativos garantidores em garantir o pagamento dos benefícios prometidos e verificando a situação financeira e atuarial do PBPREV, com base nos indicadores aplicados a partir de informações extraídas dos demonstrativos obrigatórios ora publicados pela instituição.

\section{FUNDAMENTAÇÃO TEÓRICA}

\subsection{Previdência Social no Brasil e Regimes Próprios de Previdência Social - RPPS}

A Previdência Social, estabelecida pela União, Estados, Distrito Federal e Municípios visa garantir diversos auxílios, quais sejam: auxilio doença, auxílio maternidade, acidente de trabalho, aposentadoria, seguro-desemprego e auxílio reclusão, e surge "como um mecanismo de proteção obrigatório, com a presença marcante do estado voltada a reduzir ou suprimir as necessidades sociais dos trabalhadores" (KONKEL JÚNIOR, 2005).

No Brasil, a Constituição Federal (BRASIL, 1988) define a formação do sistema previdenciário em três regimes: Regime Geral de Previdência Social (RGPS) no art. 201, o Regime Próprio de Previdência Social (RPPS), no art. 40, e os Regimes de Previdência Complementar (RPC), no art. 202. Em 2014, segundo o Dataprev existiam cerca de 5.211 .030 beneficiários dos RPPS no Brasil, e, na Paraíba, de acordo com o site de Transparência do Governo do Estado (PORTAL DA TRANSPARÊNCIA DA PARAÍBA, 2016) temos cerca de 36.865 beneficiários ligados a PBPREV em 2016.

Sendo assim, um estudo de caso foi realizado na PBPREV que, segundo o site do próprio RPPS, criada em 30 de dezembro de 2003 através da Lei n 7.517 (PARAÍBA, 2003), é uma autarquia estadual que é responsável pelo gerenciamento e operacionalização de regime de previdência dos servidores ativos e inativos do estado da Paraíba.

Já os Regimes Próprios de Previdência Social são exclusivos das esferas governamentais: União, Estados, Distrito Federal e Municípios. Possuem as mesmas prerrogativas do Regime Geral de Previdência Social - RGPS e tem as mesmas finalidades de assegurar aos servidores públicos os benefícios e assistências sociais.

Nesse sentido a Lei $\mathrm{n}^{\circ} 9.717$ (BRASIL, 1998), em seu art. $1^{\circ}$, define que os Regimes Próprios de Previdência Social dos Servidores Públicos da União, dos Estados, dos Municípios e do Distrito Federal deverão ser organizados, baseados em normas gerais e de atuária, de modo a garantir o equilíbrio financeiro e atuarial.

Para que os RPPS sejam sustentáveis, eles devem obedecer a várias regras e procedimentos desde as avaliações atuariais, tendo como financiadores de recursos a União, os Estados, os Municípios o Distrito Federal e as contribuições do pessoal civil e militar, ademais, tendo um número mínimo de participantes ou segurados de acordo com as Portarias MPS nº 402 e 403.

\subsection{Regimes Financeiros}

Para financiar os gastos, os regimes de previdência utilizam três metodologias, são elas: regime de repartição simples, regime de capitalização e regime de repartição de capitais de cobertura. Nesse sentido financiar os regimes previdenciários é estabelecer uma metodologia de captação dos RCGC | UFF | Niterói/RJ | V.1 | n.1 | jan-jun. 2018 | p. 3-15 
recursos e dos valores a serem arrecadados para que sejam administrados e retonados para os seus beneficiários na condição de auxilio ou benefícios.

Desta forma, Gushiken et al. (2002), o regime de financiamento é o mecanismo ou método que permitirá o cálculo da contribuição necessária para dar plena cobertura financeira ao valor atual dos benefícios futuros do plano, sendo o método que tornará possível a determinação de quanto será vertido ao plano para o completo financiamento do custo previdenciário.

A Portaria MPS n ${ }^{\circ} 403$ (BRASIL, 2008) dispõe os três tipos de regimes de financiamentos, podendo os regimes próprios de previdência social adotarem os seguintes tipos: Regime Financeiro de Capitalização, Regime Financeiro de Repartição de Capitais de Cobertura e o Regime Financeiro de Repartição Simples.

O método da repartição simples não se preocupa com a formação de reservas, estando voltado apenas para financiar os pagamentos correntes em determinado ano e sem exigir a constituição de reservas, cujo mutualismo é a característica marcante. Para Lima e Diniz (2016) as contribuições financeiras são determinadas para um período suficiente para dar cobertura aos benefícios dos participantes.

De acordo com Rodrigues (2002) é um sistema pelo qual o que se arrecada é imediatamente gasto, sem que haja, obrigatoriamente, um processo de poupança ou acumulação de recursos e ainda pra Cordeiro Filho (2014, p. 177) “o regime de repartição simples tem como por base o princípio do mutualismo simples, onde as contribuições dos participantes e da entidade são utilizadas para os pagamentos de todas as aposentadorias, pensões e benefícios dos também participantes desse regime". Em suma, o regime de repartição simples apresenta a característica solidariedade, ou seja, as gerações atuais contribuem para que as gerações de inativos possam receber.

De acordo com o DRAA de 2015, a PBPREV adota o regime financeiro de repartição simples para o auxílio doença, salário família, salário maternidade e auxilio reclusão. Esse regime financeiro também é denominado de método orçamentário, pressupondo o equilíbrio financeiro e atuarial constante, pois se confronta com a receita das contribuições com as despesas dos benefícios concedidos.

Já o Regime Financeiro de Capitalização tem a finalidade de formar reservas ou provisões matemáticas para cada participante, garantindo que suas contribuições lhe garantam seus benefícios futuros. Segundo Rodrigues (2002), pressupõe a acumulação de valores (contribuições) durante a fase ativa do indivíduo no mercado de trabalho, para que essa poupança possa suportar os custos de inativação no futuro. Além disso, para Lima e Diniz (2016) o regime de capitalização é conhecido como o regime de pré-pagamento ou pré-financiamento, ou seja, preocupando-se com a formação de recursos garantidores para dar cobertura aos compromissos futuros do plano.

Com a capitalização dos recursos, os déficits, ora muitos elevados por parte do governo minimizam-se, pois as perdas e os ganhos são suportados pelos participantes do plano. A PBPREV utiliza-se desse regime financeiro de capitalização na forma agregada para as aposentadorias por idade, aposentadoria por invalidez permanente e na pensão por morte de servidor em atividade. Entende-se, por método agregado, a identificação dos compromissos do plano, considerando para tanto, os servidores pela idade na data base da avaliação.

O terceiro regime, o de Repartição de Capitais por Cobertura, é uma modalidade que utiliza as características dos regimes de repartição simples e de capitalização, na qual são determinadas as contribuições necessárias para os pagamentos dos benefícios de determinado período e mais a constituição de reservas financeiras para garantir o pagamento futuro dos benefícios (LIMA; DINIZ, 2016)

Nesse sentido, Póvoas (1985) declara que a expressão "capital de cobertura" significa a parte do montante das contribuições cobradas no ano, o que, a cada um dos benefícios nascidos nesse exercício, permitirá, no conjunto da respectiva carteira de riscos, devidamente capitalizadas, garantir o pagamento do benefício ao longo do período que lhe respeita.

Para Cordeiro Filho (2014), os regimes de capitais de cobertura têm os valores de cobertura considerados os dados ou informações de caráter biométrico dos participantes como a idade, e as 
probabilidades dos riscos daí decorrentes, além de outros fatores, chamado em matemática atuarial de estudo das reservas.

Sendo assim, o regime financeiro de repartição de capitais por cobertura é formatado para que as contribuições pagas por todos sejam suficientes para formar a reserva matemática dos benefícios concedidos bem como suprir os eventos decorrentes nesse período. A PBPREV não adota esse tipo de regime.

Os regimes próprios devem obedecer ao equilíbrio financeiro e atuarial, a cada ano que passa, as reavaliações são feitas para que os dados projetados sejam apreciados com a verificação se as metas atuariais foram atingidas. A Portaria MPS n 403 (MPS, 2008) define os parâmetros técnicos e as condições a serem observadas.

De acordo com o artigo $2^{\circ}$, inciso I, da portaria supracitada, o equilíbrio financeiro representa a garantia de equivalência entre as receitas auferidas e as obrigações dos RPPS em cada exercício financeiro. Logo o equilíbrio financeiro é atingido quando o que se arrecada é suficiente para custear os benefícios.

Ademais, o equilíbrio atuarial representa a garantia da equivalência, a valor presente, entre o fluxo das receitas estimadas e das obrigações projetadas, apuradas atuarialmente a longo prazo.

Dessa forma, Tavares (2011) afirma que o regime geral deve ser compreendido como um sistema seguro que protege o direito fundamental a previdência. De um lado, com a finalidade de garantir o sustento do trabalhador, e do outro não deve onerar indevidamente o grupo protegido e a sociedade. Logo o papel do equilíbrio atuarial e financeiro é essencial para o sistema.

\subsection{Indicadores Baseados em Ativos e Passivos Atuariais}

Os indicadores baseados nos ativos e em passivos atuariais tem o objetivo de evidenciar de onde provem os recursos que mantém o regime previdenciário. Essa análise parte da opção do regime de financiamento escolhido dos planos de benefícios e das estimativas adotadas. De acordo com Lima e Diniz (2016), os indicadores baseados em ativos e passivos atuariais buscam capturar o status de financiamento do regime previdenciário. O Quadro 1 apresenta os indicadores e suas descrições, que servirão de base para o estudo.

Quadro 1: Descrição dos indicadores

\begin{tabular}{|c|c|}
\hline $\begin{array}{l}\text { Indicador de equilíbrio } \\
\text { atuarial }\end{array}$ & $\begin{array}{l}\text { Ocorre o equilíbrio atuarial quando o resultado desse indicador for } 1 \text {, evidenciando } \\
\text { que as contribuições arrecadadas ao pelo plano são suficientes para cobrir os } \\
\text { benefícios prometidos. }\end{array}$ \\
\hline $\begin{array}{l}\text { Indicador de situação } \\
\text { superavitária }\end{array}$ & $\begin{array}{l}\text { Nesse caso, quando indicador for maior que } 1 \text {, indica que o plano tem recursos } \\
\text { além do necessário para cobrir os benefícios prometidos. }\end{array}$ \\
\hline $\begin{array}{l}\text { Indicador de situação } \\
\text { deficitária }\end{array}$ & $\begin{array}{l}\text { Quando o resultado for menor que } 1 \text { demonstra que as contribuições arrecadadas } \\
\text { pelo plano não são suficientes para cobrir os benefícios prometidos. }\end{array}$ \\
\hline $\begin{array}{l}\text { Indicador de proteção dos } \\
\text { benefícios }\end{array}$ & $\begin{array}{l}\text { Esse indicador é medido pela relação entre os ativos garantidores e o valor presente } \\
\text { de todas as obrigações futuras do plano referente aos benefícios concedidos e a } \\
\text { conceder. Esse indicador retrata em percentual a formação de reservas financeiras } \\
\text { para aplicar em ativos garantidores. }\end{array}$ \\
\hline Indicador de Reservas & $\begin{array}{l}\text { Expressa a relação entre os ativos garantidores e o valor presente das obrigações } \\
\text { futuras do plano, indica em termos percentuais as reservas já constituídas do ente, } \\
\text { quanto maior melhor. }\end{array}$ \\
\hline $\begin{array}{l}\text { Passivo atuarial a } \\
\text { descoberto }\end{array}$ & $\begin{array}{l}\text { Esse índice representa o montante de obrigações que não possuem ativos } \\
\text { garantidores que lastreiem o passivo. Acontece quando passivo atuarial é maior } \\
\text { que os ativos garantidores. }\end{array}$ \\
\hline $\begin{array}{l}\text { Passivo atuarial a } \\
\text { descoberto per capta }\end{array}$ & $\begin{array}{l}\text { Esse indicador demonstra a representatividade do passivo atuarial a descoberto em } \\
\text { relação ao tamanho da comunidade evidenciando a obrigação que corresponde a } \\
\text { cada um dos cidadãos. Quanto maior esse indicador maior a carga da divida do } \\
\text { ente com a população. }\end{array}$ \\
\hline
\end{tabular}

RCGC | UFF | Niterói/RJ | V.1 | n.1 | jan-jun. 2018 | p. 3-15 


\section{Continua o Quadro 1}

\begin{tabular}{|c|l|}
\hline $\begin{array}{c}\text { Peso relativo do passivo } \\
\text { atuarial a descoberto }\end{array}$ & $\begin{array}{l}\text { Esse indicador demonstra quanto a contribuição da comunidade para amortizar o } \\
\text { passivo atuarial a descoberto. Mostra toda a potencialidade de exploração pelo } \\
\text { governo para financiar as obrigações que não tem lastro. }\end{array}$ \\
\hline $\begin{array}{c}\text { Indicador de cobertura do } \\
\text { passivo atuarial }\end{array}$ & $\begin{array}{l}\text { Demonstra a capacidade em cumprir com os benefícios prometidos em relação com } \\
\text { os recursos garantidores e as obrigações de longo prazo se assemelha ao indicador } \\
\text { de equilíbrio atuarial quanto maior melhor. }\end{array}$ \\
\hline $\begin{array}{c}\text { Relação déficit } \\
\text { atuarial/RCL }\end{array}$ & $\begin{array}{l}\text { Tem o objetivo de comparar o déficit atuarial com a receita corrente liquida anual. } \\
\text { Indica que parcelas expressivas do orçamento do estado terão que ser destinadas } \\
\text { para a cobertura do déficit. Foram criadas cinco faixas: a) Critica (mais 300\%): o } \\
\text { déficit é mais de 300\% da RCL; b) Preocupante (mais 200\% até 300\%); c) } \\
\text { Razoável mais de } 100 \% \text { até } 200 \% \text { d) Confortável até 100\% e e) Superavitária onde } \\
\text { não possui déficit atuarial }\end{array}$ \\
$\begin{array}{c}\text { Indicador de equilíbrio } \\
\text { financeiro }\end{array}$ & $\begin{array}{l}\text { Esse índice avalia se todas as contribuições dos segurados, toda as transferências } \\
\text { governamentais e os rendimentos das aplicações, são suficientes para pagar todos } \\
\text { os benefícios previdenciários já concedidos e demais obrigações decorrentes de } \\
\text { gastos administrativos. }\end{array}$ \\
\hline $\begin{array}{c}\text { Ativos/Benefícios anuais } \\
\text { pagos }\end{array}$ & $\begin{array}{l}\text { Esse indicador mostra o número de anos ou meses de pagamentos de benefícios } \\
\text { que serão cobertos pelos ativos garantidores, quanto maior melhor. }\end{array}$ \\
\hline
\end{tabular}
Fonte: Adaptado de Lima e Diniz (2016)

Todavia, a mensuração desses indicadores depende do método de financiamento, plano de benefício dos segurados e de estimativas fundadas em premissas atuariais.

\section{METODOLOGIA}

Quantos aos objetivos, a pesquisa foi classificada como documental, pois teve como objetivo evidenciar a situação financeira e atuarial da PBPREV através de indicadores, para Lakatos e Marconi (2017 p. 17) "a análise documental permite passar de um documento bruto para um documento secundário". Corroborando, Martins e Theóphilo (2009) apontam que a estratégia de pesquisa documental é característica dos estudos que utilizam documentos como fonte de dados, informações e evidências.

O objeto desta pesquisa possui uma base de segurados com um total de 50.544 segurados ativos e 42.671 segurados inativos e pensionistas, distribuídos nas seguintes modalidades: Servidores Civis, Militares, Aposentados, Reformados e Pensionistas dos Poderes Executivo, Legislativo, Judiciário, Tribunal de Contas e do Ministério Público.

Dentre as prerrogativas e atribuições da PBPREV, encontram-se concentrados os procedimentos administrativos de concessão de aposentadorias, reformas, pensão por morte e auxilio reclusão. Sua missão é a de gerir o Regime Próprio de Previdência dos Servidores Públicos efetivos do estado da Paraíba, conforme as regras e os princípios jurídicos emanados no art. 40 da Constituição Federal (BRASIL, 1988) e das Emendas Constitucionais n 20, $\mathrm{n}^{\circ} 41$ e ${ }^{\circ} 47$ (BRASIL, 1998, 2003, 2005).

Na gestão previdenciária, a PBPREV envolve as atividades de controle e de arrecadação das contribuições patronal e dos servidores, tendo-se em vista a concessão, o pagamento e a manutenção dos aposentados, reformas e pensões por morte devidas aos segurados do regime de previdência. Assim, através das análises dos relatórios da PBPREV, foram coletadas as informações necessárias para atender o objetivo da pesquisa.

A coleta dos dados foi realizada tanto no site do próprio instituto como nas informações abertas disponíveis no endereço eletrônico do CADPREV da Previdência Social. Nos sites analisados, foram selecionados os materiais necessários para compor o estudo, e, na sequência, foram separados, 
e depois, baixados, para assim, serem tratados na outra etapa da pesquisa, as fontes utilizadas estão dispostas no Quadro 2.

Quadro 2: Endereços eletrônicos das fontes da pesquisa

\begin{tabular}{|l|l|}
\hline \multicolumn{1}{|c|}{ Local } & \multicolumn{1}{|c|}{ Endereço Eletrônico } \\
\hline Palácio do Planalto & http://www.planalto.gov.br \\
\hline PBPREV & http://www.pbprev.pb.gov.br/pbprev/a-previdencia/a-instituicao-1 \\
\hline $\begin{array}{l}\text { Sistemas de informação dos Regimes } \\
\text { Públicos de Previdência Social }\end{array}$ & http://cadprev.previdencia.gov.br/Cadprev/faces/pages/index.xhtml \\
\hline $\begin{array}{l}\text { Tribunal de Contas do Estado da } \\
\text { Paraíba }\end{array}$ & https://tramita.tce.pb.gov.br/tramita/pages/main.jsf \\
\hline $\begin{array}{l}\text { Sistema de Legislação da Previdência } \\
\text { Social }\end{array}$ & http://sislex.previdencia.gov.br/paginas/72/MPS-CGPC/2005/16.htm \\
\hline
\end{tabular}

Fonte: Dados da Pesquisa (2017)

Os dados coletados, cujas fontes são citadas no Quadro 3, foram analisados através dos modelos de indicadores baseados em ativos e passivos atuariais, cálculo dos indicadores dos equilíbrios atuariais, e baseados nos fluxos de recursos. Estes indicadores foram fundamentados nos estudos de Lima e Diniz (2016, p. 412-413). O Quadro 3 apresenta os indicadores e a respectiva fórmula para se chegar aos mesmos, utilizando os dados numéricos coletados pelo estudo.

Quadro 3: Indicadores

\begin{tabular}{|c|c|c|}
\hline Indicador de equilíbrio atuarial & \multirow{3}{*}{$\begin{array}{c}\text { Valor Presente Esperado } \\
\text { das Contribuiçóes } \\
\text { Valor Presente das Obrigaçães } \\
\text { Futuras de Beneficios Concedidos } \\
\text { e a Conceder }\end{array}$} & \multirow{3}{*}{$\begin{array}{l}<1=\text { déficit, se for }=1 \text { está com } \\
\text { equilíbrio e }<1 \text { superávit. }\end{array}$} \\
\hline $\begin{array}{l}\text { Indicador de situação } \\
\text { superavitária }\end{array}$ & & \\
\hline Indicador de situação deficitária & & \\
\hline & Ativos Garantidores & \multirow[b]{2}{*}{$\begin{array}{c}\text { \% da formação de reservas financeiras } \\
\text { para aplicar em ativos garantidores }\end{array}$} \\
\hline $\begin{array}{l}\text { Indicador de proteção dos } \\
\text { benefícios }\end{array}$ & $\begin{array}{c}\text { Valor Presente das Obrigaçães } \\
\text { Futuras de Beneficios Concedidos } \\
\text { e a Conceder }\end{array}$ & \\
\hline & Ativos Garantidores & \multirow[b]{2}{*}{$\begin{array}{l}\% \text { das reservas constituídas, quanto } \\
\text { maior melhor }\end{array}$} \\
\hline Indicador de Reservas & $\begin{array}{c}\text { Valor Presente das Obrigaçàes } \\
\text { Futuras de Beneficios Concedidos } \\
\text { e a Conceder }\end{array}$ & \\
\hline Passivo atuarial a descoberto & $\frac{\text { Déficit Atuarial }}{\text { Ativos Garantidores }}$ & $\begin{array}{l}\text { Quando o passivo atuarial é maior que } \\
\text { os ativos garantidores }\end{array}$ \\
\hline $\begin{array}{l}\text { Passivo atuarial a descoberto per } \\
\text { capta }\end{array}$ & $\frac{\text { Passivio Atuarial a Descoberto }}{\text { População }}$ & $\begin{array}{l}\text { Quanto maior o indicador, maior a } \\
\text { carga da dívida do ente com a } \\
\text { população. }\end{array}$ \\
\hline $\begin{array}{l}\text { Peso relativo do passivo atuarial a } \\
\text { descoberto }\end{array}$ & $\frac{\text { Passivvo Atuarial a Descoberto }}{\text { Renda da População }}$ & $\begin{array}{c}\text { Potencial do governo para financiar as } \\
\text { obrigações que não tem lastro }\end{array}$ \\
\hline $\begin{array}{c}\text { Indicador de cobertura do passivo } \\
\text { atuarial }\end{array}$ & $\frac{\text { Ativos Garantidores }}{\text { Déficit Atuarial }}$ & $\begin{array}{c}\text { Capacidade em cumprir os benefícios, } \\
\text { quanto maior melhor }\end{array}$ \\
\hline Relação déficit atuarial/RCL & $\begin{array}{c}\text { Déficit Atuarial } \\
\text { Receita de Contrïbuição do Periodo } \\
\text { (Receitas Totais) + } \\
\text { Ativos Garantidores }\end{array}$ & $\begin{array}{l}\text { Comparar o déficit atuarial com a } \\
\text { receita corrente líquida anual }\end{array}$ \\
\hline
\end{tabular}


Continua Quadro 3

\begin{tabular}{|c|c|c|}
\hline Indicador de equilíbrio financeiro & Receitas Totais & $\begin{array}{c}\text { Se tem recursos para pagar todos os } \\
\text { benefícios e demais obrigações }\end{array}$ \\
\hline Ativos/Benefótos Totais & Ativos Garantidores & $\begin{array}{c}\text { Número de anos ou meses de } \\
\text { pagamentos de benefícios que serão } \\
\text { cobertos pelos ativos garantidores, } \\
\text { quanto maior melhor. }\end{array}$ \\
\hline
\end{tabular}

Fonte: Adaptado de Lima e Diniz (2016)

Os indicadores apontados no Quadro 4 foram aplicados nos dados extraídos dos balanços financeiros, orçamentários e patrimonial, dos DRAA dos anos de 2013 a 2016 da PBPREV. O universo da pesquisa foi Instituto de Previdência do Estado da Paraíba PB-PREV, e a amostra foram os relatórios (balanços financeiros, orçamentários e patrimonial, como também o DRAA) divulgados nos sites da instituição e no CADPREV do Ministério da Previdência dos anos de 2013 a 2016, por estarem disponíveis no portal da PBPREV.

Os dados coletados foram agrupados, colocados em planilhas eletrônicas, e na sequência, foram aplicadas as fórmulas dos indicadores para se obter os resultados dos índices de cada equação citada no Quadro 3. Os resultados do estudo estão dispostos na sessão 4 deste trabalho.

\section{ANÁLISE DOS RESULTADOS}

Nesta sessão, serão apresentados os resultados obtidos diante da análise dos dados extraídos dos balanços financeiros, orçamentários e patrimoniais e da DRAA nos anos de 2013 a 2016 da PBPREV. Os dados estão em formato de indicadores, para avaliar os resultados e os seu significado, no que se refere à situação financeira e atuarial da entidade.

Com base nos dados coletados, e a respectiva aplicação dos indicadores citados no Quadro 3, foram elaboradas as tabelas constantes nesta sessão, que serviram de base para evidenciar os resultados obtidos pelo estudo. O estudo inicialmente buscou analisar através dos indicadores, qual o equilíbrio atuarial do PBPREV nos anos analisados, cujos dados estão dispostos na Tabela 1.

Tabela 1: Equilíbrio atuarial

\begin{tabular}{llll}
\hline $\mathbf{2 0 1 3}$ & $\mathbf{2 0 1 4}$ & $\mathbf{2 0 1 5}$ & $\mathbf{2 0 1 6}$ \\
\hline 0,88 & 0,70 & 1,12 & 0,79 \\
\hline \multicolumn{4}{c}{ Fonte: Elaboração própria (2017) }
\end{tabular}

A partir dos indicadores financeiros da PBPREV, evidencia-se que, na série histórica, existe uma oscilação dos valores presentes das contribuições dos segurados, frente ao fluxo projetado dos benefícios previdenciários concedidos e a conceder. Consoante os dados apresentados, em 2013, para cada obrigação futura trazida a valor presente o ente possuía, $88 \%$ de recursos foram cobertos pelas contribuições previdenciárias esperadas, variando para 70\% em 2014. Em 2015, este indicador apresentou alta, passando para $112 \%$ e decrescendo consideravelmente para $79 \%$, no último período de análise, em 2016.

Este fato pode indicar uma possível tendência para o déficit, tendo em vista que o único ano que demonstrou uma situação satisfatória (acima de 1) foi em 2015, na qual o RPPS teve superávit, entretanto, quando analisados os anos de forma geral, a entidade apresentou maiores situações de déficit do que superávit ou de equilíbrio atuarial.

Continuando a análise, foi realizado o cálculo percentual para identificar a proteção dos benefícios, e, os respectivos resultados, que se apresentam na Tabela 2.

Tabela 2: Proteção dos benefícios

\begin{tabular}{cccc}
\hline $\mathbf{2 0 1 3}$ & $\mathbf{2 0 1 4}$ & $\mathbf{2 0 1 5}$ & $\mathbf{2 0 1 6}$ \\
\hline 7,28 & 4,65 & 3,34 & 1,43 \\
\hline \multicolumn{4}{c}{ Fonte: Elaboração própria (2017) }
\end{tabular}


Evidencia-se que, conforme os resultados da Tabela 2, a entidade vem decrescendo na capacidade de ter ativos garantidores. Isto significa que as reservas financeiras estão reduzindo, indicando que o RPPS não está produzindo reservas financeiras suficientes para aplicar em ativos garantidores, o que pode comprometer o equilíbrio financeiro e atuarial do ente.

Depois de analisada a situação dos ativos garantidores, o estudo buscou evidenciar o indicador de reservas, cujos resultados estão evidenciados na Tabela 3.

Tabela 3: Reservas

\begin{tabular}{cccc}
\multicolumn{5}{c}{ Tabela 3: Reservas } \\
\hline $\mathbf{2 0 1 3}$ & $\mathbf{2 0 1 4}$ & $\mathbf{2 0 1 5}$ & $\mathbf{2 0 1 6}$ \\
\hline 9,41 & 5,89 & 8,14 & 11,27 \\
\hline \multicolumn{4}{c}{ Fonte: Elaboração própria (2017) }
\end{tabular}

O indicador de reservas reflete a relação entre os ativos garantidores e o valor presente das obrigações futuras do plano, indica em termos percentuais as reservas já constituídas do ente, quanto maior melhor. Conforme a Tabela 3, identificou-se uma baixa entre os anos de 2013 e 2014, mas com respectiva recuperação nos anos de 2015 e 2016, último período de análise. No entanto, apesar da recuperação de 2015 e 2016, entende-se, a partir de uma leitura crítica deste índice, que o mesmo precisa ser melhorado, pois os segurados ou beneficiários estão utilizando o benefício, e a PBPREV ainda consegue suprir o pagamento desses os benefícios atuais, devido ainda às transferências governamentais.

Continuando com a avaliação, o estudo buscou evidenciar a relação entre ativos garantidores e benefícios pagos, e os resultados desta relação estão na Tabela 4.

Tabela 4: Relação entre ativos garantidores e benefícios pagos

\begin{tabular}{llll}
\hline $\mathbf{2 0 1 3}$ & $\mathbf{2 0 1 4}$ & $\mathbf{2 0 1 5}$ & $\mathbf{2 0 1 6}$ \\
\hline 8,12 & 287,37 & 69,77 & 31,32 \\
\hline
\end{tabular}

Fonte: Elaboração própria (2017)

A ideia deste índice é que, quanto maior o percentual, melhor, logo, conforme os resultados obtidos pelo estudo, esta relação dos ativos garantidores frente aos benefícios anuais pagos representa uma tendência de queda, mostrando que no ano de 2016 a PBPREV teria 31,32\%, o que custearia apenas três meses e sete dias em relação aos benefícios anuais, e que não dariam para custear os benefícios se não fossem as contribuições repassadas para a PBPREV. Isto se deu pela intensa atividade previdenciária, com a implantação do "PBPREV AGILIZA" que possibilitou a análise e concessão do benefício em 30 dias.

Isto foi decorrente, pois, no ano de 2013, foram concedidas 3.385 revisões, benefícios e aposentadorias e com a implementação desse sistema, em 2014, esse número aumentou para 5.044, uma crescente de $67,10 \%$ na atividade previdenciária da PBPREV.

Tabela 5: Passivo atuarial descoberto

\begin{tabular}{llll}
\hline $\mathbf{2 0 1 3}$ & $\mathbf{2 0 1 4}$ & $\mathbf{2 0 1 5}$ & $\mathbf{2 0 1 6}$ \\
\hline $6.371 .197,00$ & $67.138 .364,81$ & $11.022 .409,64$ & $123.185 .522,56$ \\
\hline
\end{tabular}

Fonte: Elaboração própria (2017)

O passivo atuarial a descoberto representava, em 2016, um montante de $\mathrm{R} \$ 123.185 .522,56$. Com isso, pode-se inferir que está havendo um aumento do passivo atuarial a descoberto. Essa situação precisa ser analisada com cautela, em virtude da diminuição dos ativos garantidores para que possam cobrir as obrigações futuras. Logo, buscando aumentar a quantidade de informações sobre o passivo atuarial a descoberto, foi montada a Tabela 6 . 
Tabela 6: Passivo atuarial a descoberto per capta

\begin{tabular}{cccc}
\hline $\mathbf{2 0 1 3}$ & $\mathbf{2 0 1 4}$ & $\mathbf{2 0 1 5}$ & $\mathbf{2 0 1 6}$ \\
\hline 1,63 & 17,02 & 2,77 & 30,60 \\
\hline \multicolumn{2}{c}{ Fonte: Elaboração própria (2017) }
\end{tabular}

Fonte: Elaboração própria (2017)

O passivo atuarial existe em todos os anos, no entanto, a partir da situação de 2016, apresenta uma tendência de aumento. Sendo assim, existe um déficit por pessoa de R $\$ 30,60$. Esse parâmetro deve ser avaliado em relação à renda da comunidade, PIB ou a Receita Corrente Líquida.

$\mathrm{Na}$ sequência, foram realizados os cálculos dos indicadores que apontam o potencial do governo para financiar as obrigações que não tem lastro, cujos resultados estão expostos na Tabela 7.

Tabela 7: Peso relativo passivo atuarial em relação à renda da comunidade

\begin{tabular}{llll}
\hline $\mathbf{2 0 1 3}$ & $\mathbf{2 0 1 4}$ & $\mathbf{2 0 1 5}$ & $\mathbf{2 0 1 6}$ \\
\hline 0,01 & 0,08 & 0,01 & 0,11 \\
\hline \multicolumn{4}{c}{ Fonte: Elaboração própria (2017) }
\end{tabular}

A participação do passivo atuarial em relação à população é inexpressiva (cerca de $11 \%$ ), e, com isso o governo pode explorar bem as suas receitas, sem gerar medidas impopulares, com o aumento de impostos, revelando uma situação confortável. O estudo buscou evidenciar a capacidade de cumprir os benefícios, os resultados estão evidenciados na Tabela 8.

Tabela 8: Indicador de cobertura do passivo atuarial (ativos garantidores)

\begin{tabular}{cccc}
\hline $\mathbf{2 0 1 3}$ & $\mathbf{2 0 1 4}$ & $\mathbf{2 0 1 5}$ & $\mathbf{2 0 1 6}$ \\
\hline 0,95 & 4,24 & 1,26 & 0,13 \\
\hline \multicolumn{4}{c}{ Fonte: Elaboração própria (2017) }
\end{tabular}

Os resultados relacionados ao indicador de cobertura do passivo atuarial se mostram menores que 1 em 2016. Isso significa dizer que o montante de ativos garantidores não é suficiente para garantir o passivo atuarial, revelando, assim, a existência do passivo a descoberto.

Como a apresentação deste indicador está relacionada à grandeza, quanto maior melhor, a relação histórica demonstra uma queda de 2014 até 2016. Através dos indicadores, foi possível evidenciar a relação de déficit atuarial com a receita corrente líquida, com os resultados apresentados na Tabela 9.

Tabela 9: Relação déficit atuarial com a receita corrente líquida

\begin{tabular}{cccc}
\hline $\mathbf{2 0 1 3}$ & $\mathbf{2 0 1 4}$ & $\mathbf{2 0 1 5}$ & $\mathbf{2 0 1 6}$ \\
\hline 1,19 & 0,01 & 0,02 & 0,08 \\
\hline \multicolumn{4}{c}{ Fonte: Elaboração própria (2017) }
\end{tabular}

Quanto em relação ao Déficit Atuarial/RCL observa-se que, apenas no ano de 2013, a situação era confortável, pois $119 \%$ da receita corrente líquida cobria todo o déficit atuarial, porém, a partir de 2014, o resultado apresenta-se baixo.

Em 2016, 8\% da receita corrente líquida estava destinada a cobertura do déficit, o que pode está revelando uma situação preocupante, tendo em vista a forma de recursos que entram na entidade, e sua necessidade de fazer com que o mesmo gere uma situação de equilíbrio para o plano. $\mathrm{O}$ estudo levantou, também, os indicadores financeiros do período analisado pela pesquisa, e estes resultados estão dispostos na Tabela 10.

Tabela 10: Indicador de equilíbrio financeiro

\begin{tabular}{cccc}
\hline $\mathbf{2 0 1 3}$ & $\mathbf{2 0 1 4}$ & $\mathbf{2 0 1 5}$ & $\mathbf{2 0 1 6}$ \\
\hline 1,02 & 1,00 & 1,00 & 1,00 \\
\hline \multicolumn{4}{c}{ Fonte: Elaboração própria (2017) }
\end{tabular}

Evidencia-se, conforme a Tabela 10, que o Indicador de Equilíbrio Financeiro se mantém constante nos últimos anos. Este equilíbrio provavelmente se deve ao fato do governo estar RCGC | UFF | Niterói/RJ | V.1 | n.1 | jan-jun. 2018 | p. 3-15 
continuamente transferindo recursos para honrar os benefícios presentes, o que pode refletir uma preocupação com o equilíbrio entre as receitas totais e os respectivos pagamentos atrelados a estes recursos.

\section{CONSIDERAÇÕES FINAIS}

O presente estudo teve como objetivo evidenciar a situação financeira e atuarial da PBPREV através dos indicadores adaptados por Lima e Diniz (2016). Para atender o objetivo proposto pela pesquisa, foram extraídos os dados dos balanços financeiros e patrimoniais, além de outras demonstrações da entidade no período de 2013 a 2016. Utilizando-se esses dados, foram aplicadas as fórmulas de cada indicador, para verificar a situação financeira e atuarial do instituto. Com base nas análises realizadas, foi evidenciado que a situação atuarial do PBPREV se apresenta com uma tendência para o déficit, mas com sua situação financeira, equilibrada, em virtude dos recursos provenientes das transferências governamentais, além das que são previstas nos cálculos atuariais, no entanto, mas que, em todo o período analisado, encontra-se no limite.

O estudo concluiu que o PBPREV não possui uma condição financeira e atuarial satisfatória, a qual possa garantir a continuidade das atividades do instituto no médio prazo. Os indicadores calculados demonstraram uma redução expressiva nos ativos garantidores ao longo do período analisado, gerando um passivo atuarial a descoberto com tendência crescente para o déficit, comprometendo assim, a solvência do ente. Como medida corretiva e para suprir as insuficiências de recursos, o Governo estadual realiza transferências financeiras para cobrir os benefícios atuais e futuros.

Com base nas conclusões, evidencia-se a necessidade de uma revisão nos recursos que entram na entidade, como também, as aplicações de medidas corretivas que busquem garantir o equilíbrio financeiro e atuarial do ente, esses procedimentos, podem ajudar a corrigir alguns problemas que possam estar comprometendo a capacidade de garantir os benefícios prometidos PBPREV.

A principal limitação para este estudo foi o levantamento dos dados, tendo em vista a busca ter sido realizada em vários sites. Outro ponto está relacionado à necessidade de identificação e separação dos dados que pudessem atender ao objetivo traçado pela pesquisa.

Espera-se que os resultados obtidos motivem a realização de novos trabalhos, com a intenção de agregar aos estudos existentes, relacionados ao equilíbrio financeiro e atuarial dos RPPS. Recomenda-se para futuras pesquisas, a utilização de novos períodos, para que se possa estabelecer um comparativo entres os resultados obtidos, assim como, amostras de outros RPPSs.

\section{REFERÊNCIAS}

BRASIL. Constituição da República Federativa do Brasil de 1988. Diário Oficial [da] República Federativa do Brasil, Brasília, DF, 5 out. 1988. Disponível em: http://www .planalto.gov.br/ccivil_03/constituicao/constituicao.htm>. Acesso em: 16 nov. 2017.

. Lei n ${ }^{\circ} 9.717$, de 27 de novembro de 1998. Dispõe sobre regras gerais para a organização e o funcionamento dos regimes próprios de previdência social dos servidores públicos da União, dos Estados, do Distrito Federal e dos Municípios, dos militares dos Estados e do Distrito Federal e dá outras providências. Diário Oficial [da] República Federativa do Brasil, Brasília, DF, 27 nov. 1998. Disponível em: http://www. planalto.gov.br/ccivil 03/leis/L9717.htm>. Acesso em: 03 dez. 2017.

Ministério da Previdência Social. Portaria MPS no 402, de 10 de dezembro de 2008 Republicação. Disciplina os parâmetros e as diretrizes gerais para organização e funcionamento dos regimes próprios de previdência social dos servidores públicos ocupantes de cargos efetivos da União, dos Estados, do Distrito Federal e dos Municípios, em cumprimento das Leis $n^{\circ} 9.717$, de 1998 e $n^{\circ}$ 10.887, de 2004. Diário Oficial [da] República Federativa do Brasil, Brasília, DF, 11 dez. 2008. 
Disponível em: $<$ http://sislex. previdencia.gov.br/paginas/66/MPS/2008/402_1.htm $>$ Acesso em: 03 dez. 2017.

. Ministério da Previdência Social. Portaria MPS nº 403, de 10 de dezembro de 2008. Dispõe sobre as normas aplicáveis às avaliações e reavaliações atuariais dos Regimes Próprios de Previdência Social - RPPS da União, dos Estados, do Distrito Federal e dos Municípios, define parâmetros para a segregação da massa e dá outras providências. Diário Oficial [da] República Federativa do Brasil, Brasília, DF, 11 dez. 2008. Disponível em: http://sislex.previdencia.gov.br/paginas/66/MPS/2008/403 1.htm> Acesso em: 03 dez. 2017.

. Emenda Constitucional no 43, de 19 de dezembro de 2003. Modifica os arts. 37, 40, 42, 48, 96, 149 e 201 da Constituição Federal, revoga o inciso IX do $\S 3$ do art. 142 da Constituição Federal e dispositivos da Emenda Constitucional n ${ }^{\circ}$ 20, de 15 de dezembro de 1998, e dá outras providências. Diário Oficial [da] República Federativa do Brasil, Brasília, DF, 31 dez. 2003. Disponível em: http://www.planalto.gov.br/ccivil 03/constituicao/emendas/emc/emc41.htm>. Acesso em: 03 dez. 2017.

Conselho Monetário Nacional. Resolução no 3.922, de 25 de novembro de 2010. Dispõe sobre as aplicações dos recursos em moeda corrente dos regimes próprios de previdência social instituídos pela União, Estados, Distrito Federal e Municípios. Diário Oficial [da] República

Federativa do Brasil, Brasília, DF, 25 nov. 2010. Disponível em: < http://www.bcb.gov.br/pre/normativos/busca/downloadNormativo.asp?arquivo=/Lists/Normativos/ Attachments/49510/Res_3922_v1_O.pdf > Acesso em: 17 nov. 2017.

. Ministério da Previdência Social. Portaria MPS no 519, de 24 de agosto de 2011. Dispõe sobre as aplicações dos recursos financeiros dos Regimes Próprios de Previdência Social instituídos pela União, Estados, Distrito Federal e Municípios, altera redação da Portaria MPS no 204, de 10 de julho de 2008 e da Portaria MPS no 402, de 10 de dezembro de 2008 e 402, ambas de 2008 e dá outras providências. Diário Oficial [da] República Federativa do Brasil, Brasília, DF, 26 ago. 2011. Disponível em: < http://sislex. previdencia.gov.br/paginas/66/MPS/2011/519.htm > Acesso em: 03 dez. 2017.

CADPREV - Sistema de Informações dos Regimes Públicos de Previdência Social. Demonstrativos da Aplicação e Investimento dos Recursos - Demonstrativos até 2016. 2016. Disponível em: < http://cadprev.previdencia.gov.br/Cadprev/faces/

pages/index.xhtml;jsessionid=22AE0E6C1359276BCB2EFBD7BFD76CBA.node01 > Acesso em: 03 dez. 2017.

CORDEIRO FILHO, A. Cálculo atuarial aplicado: Teoria e aplicações, exercícios resolvidos e propostos. 2. Ed. São Paulo: Atlas, 2014.

GUSHIKEN, L.; FERRARI, A. T.; FREITAS, W. J. de; GOMES, J. V.; OLIVEIRA, R. M. F. de. Regimes próprios de previdência dos servidores: Como implementar? - uma visão teóricoprática. Brasília: MPAS, 2002. Disponível em: $<$ http://www.previdencia.gov. br/arquivos/office/3 081014-111359-413.pdf> Acesso em: 03 dez. 2017.

KONKEL JUNIOR, N. Contribuições sociais: Doutrina e jurisprudência. Quartier Latin, 2005.

LIMA, S. C. de; DINIZ, J. A. Contabilidade pública: Análise financeira e governamental. São Paulo: Atlas, 2016.

MARCONI, M. A.; LAKATOS, E. M. Metodologia do Trabalho Científico. 8 Ed. São Paulo: Atlas, 2017.

MARTINS, G. de A.; THEÓPHILO, C. R. Metodologia da investigação científica para ciências sociais aplicadas. São Paulo: Atlas, 2009. 
MINISTÉRIO DA PREVIDÊNCIA SOCIAL - MPS. Consolidação da legislação federal. 2016. Disponível em: $\quad<\quad$ http://www.previdencia.gov.br/wp-content/ uploads/2016/06/CONSOLIDACAOLEGISLACAORPPSfevereiro2016-1.pdf $>$ Acesso em: 03 dez. 2017.

PARAÍBA. Lei $n^{0}$ 9.939, de 27 de dezembro de 2012. Dispõe sobre os planos de custeio e de benefícios do regime próprio de previdência social do Estado da Paraíba, altera dispositivo à Lei $\mathrm{n}^{\mathrm{o}}$ 7.517/2003 e dá outras providências. Diário Oficial [do] Estado da Paraíba, João Pessoa, PB, 27 dez. 2012. Disponível em: < http://www.pbprev.pb.gov.br/pbprev/aprevidencia/legislacao/LEIN9.939DISPEPLANOSECUSTEIOREGIMEPREVIDNCIRIO.pdf > Acesso em: 03 dez. 2017.

PORTAL DA TRANSPARÊNCIA DA PARAÍBA. Servidores: Poder Executivo. 2016. Disponível em: $\quad<\quad$ https://sagres.tce.pb.gov.br/estado pessoal03.php?poder=1\&ano $=2016 \&$ competencia=122016\&descricao=Dezembro $>$ Acesso em: 03 dez. 2017.

PÓVOAS, M. S. S. Previdência privada: filosofia, fundamentos técnicos e conceituação jurídica. Fundação Escola Nacional de Seguros, 1985.

RODRIGUES, F. M. Fundos de pensão dos servidores públicos municipais. São Paulo: Renovar, 2002.

TRIBUNAL DE CONTAS DO ESTADO DA PARAÍBA - TCE/PB. Processo Técnico n 16.017. 2015. Disponível em: < https://publicacao.tce.pb.gov.br/cf2bee952ec562358699a28b63d0b735> Acesso em: 03 dez. 2017.

YIN, R. Case study research: Design and methods. 4. Ed. Los Angeles: Sage, 2011.

\section{SOBRE OS AUTORES}

FÁBIO MARISCANO FAGUNDES é especialista em Perícia e Auditoria/UFPE, contador na MFCONT Contabilidade Empresarial LTDA e graduado em Ciências Atuariais/UFPB.

E-mail: marsicanofagundes@hotmail.com

VERA LÚCIA CRUZ é doutoranda em Administração/Universidade Potiguar, mestra em Ciências Contábeis/UFPE. Professora Adjunta na UFPB.

E-mail: veralc22@hotmail.com

RAMON RODRIGUES DOS SANTOS é mestre em Administração/Universidade Potiguar, graduado em Ciências Contábeis pelo Centro Universitário de João Pessoa. Professor Substituto na UFPE.

E-mail: ramonrdgs@gmail.com 